\title{
Cord blood nucleated RBCs - an early marker of birth Asphyxia
}

\author{
Suganthi V. ${ }^{1}$, Jayakuamar P. ${ }^{2}$, Santhi K. ${ }^{3}$ \\ ${ }^{1}$ Dr. Suganthi. V, Professor \& HOD, Department of Pediatrics, Coimbatore Medical College Hospital, Coimbatore, \\ ${ }^{2}$ Dr. Jayakuamar. P, Assistant Professor, Department of Pediatrics, Karpagam Medical College Hospital, Coimbatore, \\ ${ }^{3}$ Dr. Santhi K, Junior Resident, Department of Pediatrics, Coimbatore Medical College Hospital, Coimbatore, Tamil \\ Nadu, India.
}

Address for Correspondence: Dr. Suganthi V, Professor \& HOD, Department of Pediatrics, Coimbatore Medical College Hospital, Coimbatore, Email: suganthi_17365@yahoo.com

\begin{abstract}
Introduction: Birth asphyxia can cause morbidity and mortality to newborn babies. One of the leading indicators of birth asphyxia is the presence of nucleated red blood corpuscles (NRBCs) in cord blood of the newborn taken at 5 minutes after delivery. We intended to study the impact of asphyxia on presence of NRBCs and the relation between NRBCs and immediate outcome of the child. Methods: The study included 170 children. About 85 children with asphyxia and 85 normal babies were considered. Inclusion criteria for study group were a 5 minute Apgar score less than 7. All data were collected from the case sheets of the newborn babies. Cord blood was collected from both groups of children, levels of NRBCs assessed and correlated with level of asphyxia and short term clinical outcomes. Results: The NRBC counts in cord blood as percentage of WBC count of newborn with asphyxia (15.76\%) was found to be significantly higher than the control group children (4.28\%). The NRBC levels also exhibited a significant negative correlation with the APGAR scores at 5 minutes. A significantly positive correlation was seen between the NRBC count and both severity of asphyxia and adverse outcomes. Conclusion: The NRBC count as percentage of WBC count in cord blood, collected 5 minutes after delivery is a simple marker for assessment of severity of asphyxia and its perinatal outcomes.
\end{abstract}

Keywords: Asphyxia neonatorum, Umbilical cord blood, Erythroblasts, Perinatal death.

\section{Introduction}

Asphyxia is defined by WHO as the failure of initiation and sustained breathing at birth [1]. The American Academy of Pediatrics has defined perinatal asphyxia based on four features [2]

1. Umbilical cord arterial $\mathrm{pH}$ below 7

2. APGAR score below 3 for more than 5 minutes

3. Neurologic manifestations

4. Multisystem organ dysfunction

Nucleated red blood cells (NRBCs) as percentage of white blood cells in cord blood has been identified as one of the parameters used to define perinatal asphyxia $[3,4,5,6]$. The fetal compensatory response to hypoxia is erythropoiesis, which results in the release of immature RBCS into the fetal circulation [7]. The present study seeks to correlate cord blood NRBCs with perinatal

Manuscript received: $20^{\text {th }}$ October 2016

Reviewed: $4^{\text {th }}$ November 2016

Author Corrected; $16^{\text {th }}$ November 2016

Accepted for Publication: $30^{\text {th }}$ November 2016 asphyxia severity, its short term outcomes and also compare it with APGAR score.

\section{Aim of the study}

Primary objective: To compare the level of NRBCs in cord blood of asphyxiated newborns with non asphyxiated newborn.

Secondary objective: To establish the levels of NRBCs in cord blood as an indicator of immediate outcome in perinatal asphyxia

Method of study- A total of 170 babies born at Coimbatore Medical College Hospital were enrolled into the study. This was divided into two groups.

Group I: Asphyxiated newborn

Group II: Normal term babies.

This was an experimental study. The sample size was statistically computed to be 170 with 85 babies in 
groups I and II. The samples were selected by judgment sampling method.

Inclusion criteria- Term neonates with perinatal asphyxia with 5 minute Apgar score less than 7/10

Exclusion criteria- Babies with any of the following criteria:

1. Newborns with severe congenital malformation

2. Chromosomal anomalies

3. TORCH infection

4. Septicemia

5. Rh incompatibility

6. Maternal diabetes mellitus

7. Multiple gestation

8. Chorioamnionitis

9. Intra uterine growth restriction

10. Mothers on medications that change blood profile

Control Group- Term newborns delivered during the same period fulfilling the following criteria were enrolled as controls.

1. APGAR score greater than $7 / 10$ at 5 minutes

2. Absence of meconium stained amniotic fluid

3. Meeting the exclusion criteria specified for the study group.
Data Collection- Before enrolling the baby in the study, an informed consent of the parents was obtained. The study was approved by the Institutional Ethics Committee of the Coimbatore Medical College Hospital.

Details of the mother were recorded, about the baby, resuscitation details and clinical assessments were recorded. These included asphyxia measures, NRBCs measure and outcome measures. The data was collected between July 2013 to August 2014.About $2 \mathrm{ml}$ of cord blood was collected at 5 minutes after birth in EDTA tubes from both study group and control group. Blood smears were used for making smears for NRBCs. Samples were analyzed by the pathologist.

Statistical Methods- Descriptive statistics were calculated for continuous variables in the study and frequency distribution was calculated for categorical variables. NRBC count was converted into categorical variable- high (more than 10) and low (0-9) counts and the association among the 2 groups was tested using the chi-square test. The impact of severity of asphyxia on NRBC counts was tested using one way ANOVA. The NRBC count association with immediate outcomes was tested using Pearson correlation.

\section{Results}

Table-1: Apgar scores among the groups.

\begin{tabular}{|c|c|}
\hline Apgar at 5 Min & Study Group \\
\hline $0-3$ & 8 \\
\hline $4-6$ & 77 \\
\hline
\end{tabular}

Majority of the babies had an APGAR score of 4-6 indicating moderate asphyxia.

Table-2: NRBC Counts in the 2 groups as categorical variables.

\begin{tabular}{|c|c|c|}
\hline NRBC Count/ 100 WBC & Study group & Control group \\
\hline $0-10$ & $23.27 \%$ & 85 \\
\hline$>10$ & $62.73 \%$ & 0 \\
\hline \multicolumn{2}{|c|}{ Chi Square Value 39.521} \\
\hline
\end{tabular}

There was a significant difference in the NRBC count/100WBC, (Corrected into categorical variables) between the study group and control group.

Table-3: Mean NRBC count in the two groups.

\begin{tabular}{|c|c|c|c|}
\hline & Cases (Mean) SD & Control (Mean) SD & P value \\
\hline $\begin{array}{c}\text { NRBC COUNT/ 100 } \\
\text { WBC }\end{array}$ & $(15.7 \pm 3.64)$ & $(4.28 \pm 2.07)$ & $<0.001$ \\
\hline
\end{tabular}

There was a significant difference in the NRBC count/ $100 \mathrm{WBC}$ in the study group $(15.7 \pm 3.64)$ when compared to the control group $(4.28 \pm 2.07)$. 
Table-4: Impact of Apgar score level on the NRBC counts.

\begin{tabular}{|c|c|}
\hline APGAR Score & NRBC count AT 5 min \\
\hline $4-6$ & $15.8 \pm 1.62$ \\
\hline $0-3$ & $17.9 \pm 2.23$ \\
\hline \multicolumn{2}{|c|}{ P value $<0.001$} \\
\hline
\end{tabular}

A one way ANOVA was used to test the impact of APGAR score on the NRBC counts after 5 minutes and it showed significant difference between average NRBC counts at various levels of the APGAR score.

Table-5: HIE Stages and NRBC count.

\begin{tabular}{|c|c|c|}
\hline HIE Stages & No. of cases & NRBC count \\
\hline 1 & 23 & $7.63 \pm 1.82$ \\
\hline 2 & 54 & $13.5 \pm 2.67$ \\
\hline 3 & 8 & $18.8 \pm 5.58$ \\
\hline \multicolumn{2}{|c|}{ P value $<0.05$} & \\
\hline
\end{tabular}

A one way ANOVA used to test the impact of HIE stage on the mean NRBC count showed a significant impact. HIE and NRBC also showed significant positive correlation. $(\mathrm{r}-0.353$, $\mathrm{P}$ value $<0.05$ )

Table-6: NRBC count and neonatal mortality.

\begin{tabular}{|c|c|c|}
\hline NRBC Count/ 100 WBC & Study Group Cases & Study Group Deaths \\
\hline $0-10$ & 23 & NIL \\
\hline$>10$ & 62 & $9.6 \%$ \\
\hline \multicolumn{2}{|c|}{ P value $<0.05$} \\
\hline
\end{tabular}

There was significant difference in deaths among the 2 groups of NRBC count.

\section{Discussion}

NRBCs are a common observation in the circulating blood of newborn. The number of $\mathrm{NRBC} / 100 \mathrm{WBC}$ is quite variable and it is usually less than $10[8]$. Perinatal asphyxia, prematurity, Rhesus sensitization and maternal diabetes mellitus are the frequent instances in which NRBCs count exceeds 10 [9,10]. In this study, all other conditions except perinatal asphyxia have been excluded as exclusion criteria.

In our study, the control group had a mean \pm SD of 4.28 $\pm 2.07 \mathrm{NRBCs}$ all the neonates were in the category 0 $10 \mathrm{NRBCS} / 100 \mathrm{WBC}$, the asphyxiated group had a mean \pm SD of $15.7 \pm 7.64,73 \%$ were in the category of more than 10 with a $P$ value of $<0.001$. Korst LM et al [11] conducted a study comparing NRBC data from 153 term neurologically impaired neonates with NRBCs of 83 term non asphyxiated newborns. The mean number of initial NRBCs was significantly higher in the neurologically impaired neonates in the control group.

Clinically higher the HIE staging higher was the mean $\mathrm{NRBC} / 100 \mathrm{WBC}$. The NRBC/ $100 \mathrm{WBC}$ was $7.63 \pm$ 1.82 in stage $1,13.5 \pm 2.67$ in stage 2 and $18.8 \pm 5.58$ in stage 3 and the $P$ value was $<0.05$. In a study by
Manjusha Goel et al [12], a total of 100 neonates were studied. Levels of NRBCs /100 WBCs in cord blood were compared for 50 asphyxiated and 50 normal neonates. They found a significant correlation $(\mathrm{P}<0.01)$ of the number of NRBCs/ 100WBC with HIE staging and mortality.

In the present study, the mortality was nil in the study group, when the NRBC COUNT/ 100WBCS were in the category $0-10$, and $9.6 \%$ in the category more than 10. Shripad Hebbar [13] conducted a study on 100 neonates. Cord blood NRBC counts were evaluated in newborns of 50 preeclamptic women and 50 healthy pregnant women.

The mean cord blood NRBC count in both the groups was significantly different, and below the count of $13 / 100$ leucocytes, adverse neonatal outcome was less likely. In a study by Ghosh et al [14], a total of 75 cases were studied. Levels of NRBC per $100 \mathrm{WBC}$ in umbilical venous blood were compared between 26 asphyxiated newborns and 49 non-asphyxiated newborns. A high NRBC count in umbilical venous blood correlated with poor early neonatal outcome. 
The limitations of the study are other diagnostic methods like cord blood gas analysis and magnetic resonance imaging were not done in asphyxiated neonates.

\section{Conclusion}

The cord blood nucleated red blood cell count is a good early marker of perinatal asphyxia and its outcome. It is cost- effective and it is a useful marker to evaluate perinatal asphyxia in resource limited settings.

Funding: Nil, Conflict of interest: Nil

Permission from IRB: Yes

\section{References}

1. World Health Organisation. Neonatal and Perinatal Mortality; Country, Regional and Global estimates, 2004. Geneva: WHO, 2006,1.25.

2. World Health Organisation. International Statistical classification of diseases and related Health Problems, Tenth Revision (ICD- 10). Chapter XVI: Certain conditions originating in perinatal period (P00- P96). Geneva: World Health Organisation, 1992.

3. Ferns S J,Bhat B V, Basu D.Value of nucleated red blood cells in predicting severity and outcome of perinatal asphyxia. Indian J Pathol Microbiol. 2004 Oct; 47(4):503-5.

4. Phelan J,Kirkendall C, Koorst L, Martin G. Nucleated red blood cells in fetal brain injury show a consistant relationship with intrapartum FHR pattern. Am J Obtet Gynecol 2003; 189(6):S165.

5. Bonebrake R,Kelly A,Flemming A. An update on nucleated red blood cells as an indicator of fetal asphyxia. Am J Obtet Gynecol 2001:185(6):S246.

6. Buonocore G, Perrone S,Gioia D,Gatti MG ,Massafra C, Agosta R, et al. Nucleated red blood cell count at birth as an index of perinatal brain damage. Am J Obstet Gynecol 1999 Dec;181(6): 1500-5.
7. Ferber A, Minior VK, Bornstein E, Michael Y, Divon F. Fetal"Non reassuring status" is associated with elevation of nucleated red blood cell counts and interleukin-6. Am J Obstet Gynecol 2005 May; 192(5): 1427-9.

8. McCarthy JM, Capullari T, Thompson Z, Zhu Y, Spellacy WN. Umbilical cord nucleated red blood cell counts: Normal values and the effect of labor. J Perinatol. 2006 Feb;26(2):89-92.

9. Tac Hwan Kil, Ji Yeon Han, Jun Bum Kim, Gyeong OK Ko, Young Hyeof Lee, Kil Young Kim, Jae Woo Lim. A study on the measurement of the nucleated red blood cell count based on birth weight and its correlation with perinatal prognosis in infants with very low birth weights. Korean J paediatr. 2011 Feb; 54(2): 69- 78 .

10. MD David W. Green, MD Francis Mimouni. Nucleated erythrocytes in healthy infants and in infants of diabetic mothers. J paediatr. Volume 116. Issue 1, January 1990, 129-131.

11. Korst LM, Phelan JP, AHN MO, Martin G1. nucleated red blood cells: An update on the marker for fetal asphyxia. Am J Obstet Gynecol. 1996 Oct;175 (4 Pt 1):843-6.

12. Manjusha Goel, Rashmi Dwivedi, Poorva Gohiya, Deeparaj Hegde. Nucleated Red Blood Cell in Cord Blood as a marker of perinatal asphyxia. Jelin Neonatol. 2013 Oct- Dec; 2(4): 179- 182. doi: 10.4103/22494847.123097 .

13. Hebbar S, Misha M, Rai L. Significance of maternal and cord blood nucleated red blood cell count in pregnancies complicated by preeclampsia. J Pregnancy. 2014;2014:496416. doi: 10.1155/2014/496416. Epub 2014 Mar 6.

14. Ghosh B, Mittal S, Kumar S, Dadhwal V. prediction of perinatal asphyxia with nucleated red blood cells in cord blood of newborns. Int J Gynaecol obstet 2003 Jun; 81 (3) :267-71.

\section{How to cite this article?}

Suganthi V, Jayakuamar P, Santhi K. Cord blood nucleated RBCs - an early marker of birth Asphyxia. Int. J Pediatr Res. 2016;3(11):810-813.doi:10.17511/ijpr.2016.i11.07. 